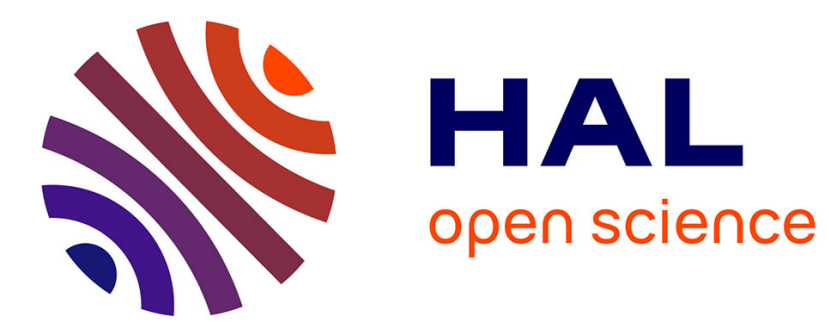

\title{
Quickly progressive amyotrophy of the thigh: An unusual cause of rapid chondrolysis of the knee
}

Maeva Ferrari, Karine Louati, Anne Miquel, Anthony Behin, Olivier

Benveniste, Jeremie Sellam

\section{- To cite this version:}

Maeva Ferrari, Karine Louati, Anne Miquel, Anthony Behin, Olivier Benveniste, et al.. Quickly progressive amyotrophy of the thigh: An unusual cause of rapid chondrolysis of the knee. Joint Bone Spine, 2015, 82 (3), pp.203-205. 10.1016/j.jbspin.2014.12.013 . hal-01117107

\section{HAL Id: hal-01117107 https://hal.sorbonne-universite.fr/hal-01117107}

Submitted on 16 Feb 2015

HAL is a multi-disciplinary open access archive for the deposit and dissemination of scientific research documents, whether they are published or not. The documents may come from teaching and research institutions in France or abroad, or from public or private research centers.
L'archive ouverte pluridisciplinaire HAL, est destinée au dépôt et à la diffusion de documents scientifiques de niveau recherche, publiés ou non, émanant des établissements d'enseignement et de recherche français ou étrangers, des laboratoires publics ou privés. 
Quickly progressive amyotrophy of the thigh: An unusual cause of rapid chondrolysis of the knee

Maeva Ferrari (1), Karine Louati (1), Anne Miquel (2), Anthony Behin (3), Olivier Benveniste

(4), Jérémie Sellam (1).

Affiliations:

1. Rhumatology, Saint Antoine Hospital, AP-HP, Inflammation-Immunopathology-Biotherapy i2B Department, Sorbonne University Paris 06, UPMC University Paris 06, INSERM, UMR_S 938, Paris, France

2. Radiology, Saint Antoine Hospital, AP-HP, Paris, France

3. Institute of myology, Pitié-Salpêtrière Hospital, AP-HP, UPMC University Paris 06, Paris, France

4. Internal Medicine Department, Pitié-Salpêtrière Hospital, AP-HP, DHU i2B, InflammationImmunopathology-Biotherapy i2B Department, Sorbonne University Paris 06, UPMC University Paris 06, Paris, France

Abstract: 224 words-1495 characters

Text: 793 words-5441 characters

Number of pages: 6

References: 10

Figures: 2

Key words : amyotrophy, myopathy, rapidly destructive osteoarthritis, femoro-patellar osteoarthritis, risk factor

Correspondance to

Prof. Jérémie Sellam

Hôpital Saint-Antoine

Service de Rhumatologie

184 rue du faubourg Saint-Antoine

75012 Paris, France

Tel : + 33149282520

Fax : + 33149282513

jeremie.sellam@sat.aphp.fr 


\section{Abstract}

While rapidly destructive OA is more recognized in hip, we report the case of a 50-year-old woman who presented a rapid chondrolysis in the patellofemoral joint in a context of rapid loss of muscular strength. She had arthralgia, myalgia and proximal muscular deficit of the limbs. Creatine phospho kinase level was elevated and electromyogram exam showed a myogenic syndrome. Neither immune nor visceral disease was highlighted. As we suspected a polymyositis, we started corticosteroids and physiotherapy, then methotrexate and intravenous immunoglobulin. Concomitantly to the worsening of the muscular deficit and atrophy of hamstrings, she developed a persistent and disabling knee pain. Initial radiographs and magnetic resonance imaging (MRI) showed only a patellofemoral dysplasia and tiny cartilage damages. Because of aggravation of myalgia, we treated by mycophenolate mofetyl then rituximab. One year later, the knee remained painful and swollen. MRI showed signs of advanced osteoarthritis including an important loss of cartilage with an atrophy of hamstrings. Several articular corticosteroids injections were done. In the same time, the evolution of the muscular disease was unusual. Another histological analysis of muscle has highlighted a genetic myopathy due to mutation of calpain. Immunosuppressive treatments were stopped and a total joint replacement was performed. We show for the first time a case of rapid chondrolysis of patellofemoral joint related to a severe genetic myopathy. 
Reduced quadriceps strength or volume is associated with patello-femoral osteoarthritis $(\mathrm{OA})(1,2)$. Rapidly destructive OA is a recognized entity in hip but may occur in knee OA (3). Here, we report a case of a rapid chondrolysis in the patellofemoral joint of a patient with rapid loss of muscular strength due to a severe myopathy.

A 50-year-old woman had myalgia, arthralgia, and proximal muscular deficit of the limbs from one year before the first visit. The rate of creatine phospho kinase (CPK) was 2856 UI/L (normal 10-160 UI/L). A myogenic syndrome was found at electromyographic exam. The antinuclear, antinuclear ribonucleoproteins, anti-synthetase (anti-J01, PL-7, PL-12, OJ, EJ), anti-SRP, anti-Mi2, anti-RNP, anti-Ro52, anti-PM-ScL, anti-Ku, and anti-3-hydroxy-3-methyl-glutaryl-CoA (HMGCoA) reductase antibodies were negative. The histology of deltoid displayed necrotized fibers, complement (C5b9) deposits on sarcolemma of some fibers and sparse inflammatory cells. No over-expression of HLA class I was observed and all the fibers were decorated in immuhistochemistry for the tested structural proteins, including dysferlin and sarcoglycans. Investigations did not identify any neoplasms nor any visceral lesions. Since a polymyositis was suspected, we started corticosteroids ( $1 \mathrm{mg} / \mathrm{kg} / \mathrm{day}$ then tapered) and physiotherapy. Because of worsening of the muscle deficit and high CPK level (around $1400 \mathrm{UI} / \mathrm{L}$ ), subcutaneous methotrexate until $20 \mathrm{mg} /$ week and intravenous immunoglobulin were added. Concomitantly, corticosteroids dosage was increased at $1 \mathrm{mg} / \mathrm{kg} / \mathrm{day}$.

Two years later, she developed pain in knees with effusions limitating walking. Clinical examination revealed an atrophy of hamstrings, adductors and gluteal deltoids. The analysis of the joint fluid showed $<100$ leucocytes $/ \mathrm{mm}^{3}$ in each knee. The initial radiographs showed a bilateral patellofemoral dysplasia without any joint space narrowing. Six months later, magnetic resonance imaging (MRI) examination of the right knee showed very tiny patellar cartilage damages corresponding to an early OA (Figure 1). Five corticosteroid injections in right knee and 3 in left knee (cortivazole and triamcinolone hexacetonide) were performed in the first 18 months with transient efficacy. 
Fourteen months after methotrexate initiation, because of the aggravation of myalgia, muscular deficit and persistent increase of CPK level at $1615 \mathrm{UI} / \mathrm{L}$, mycophenolate mofetyl (2 g/d) was added but rapidly stopped because of digestive intolerance, and replaced by rituximab (1000-mg infusion on days 1 and 15) without efficacy.

Nine months after the first knee symptoms, pain dramatically increased and the walk was possible only with a cane. One year after the first imaging evaluation, radiographs showed an almost complete joint space narrowing of patellofemoral joint. MRI showed ulcerations of patellar cartilage and a major atrophy of hamstringswith a normal quadriceps (Figure 2). Considering the functional impairment, one corticosteroid injection (triamcinolone hexacetonide) and one isotopic yttrium injection in each knee and a joint lavage of right knee were performed without efficacy. Moreover, considering the clinical and biological unusual evolution with immunosuppressive drugs, new analysis on a second muscular biopsy was performed still showing isolated necrotized fibers, atrophic fibers and internalized nuclei without inflammation. Muscle western blot showed a decrease in intensity of the calpain band, exhibiting a genetic myopathy due to mutation of calpain. Then immunosuppressive drugs and corticosteroids were stopped, while intensive physiotherapy was maintained. As the different treatments for knee OA being ineffective, a total knee joint replacement was performed 2 years after the first symptoms.

\section{Discussion}

We report a case of a rapid chondrolysis of the patellofemoral joint related to a severe myopathy. Our hypothesis is that the uncontrolled myopathy associated with long-term corticosteroid use lead to a severe and rapid amyotrophy and fatty replacement of the hamstring muscles destabilizing the femoropatellar joint.

Whereas rapid destructive hip OA is well described $(4,5)$, rapid destructive tibio-femoral OA is less known (3). To our knowledge, it is the first reported case of rapid destructive patello-femoral OA. In our patient, the rapid loss of cartilage (in 1 year) suggests a rapidly destructive knee OA according to Ayral's definiton (i.e., a loss of tibiofemoral cartilage $\geq 50 \%$ in 1 year) (3). 
In our patient, the rapid functional impairment may have lead to the dramatic decrease of the thickness of the knee cartilage as shown in tetraplegic patients $(6,7)$. Unexpectedly, we observed an involvement of the posterior muscular groups of the thigh while quadriceps remained normal, while femoro-patellar OA is actually associated to involvement of quadriceps. A possible explanation is that the balance between agonist-antagonist muscles protects joint against excessive constraints $(8,9)$ and can worse OA when it is inversed $(9,10)$. Our patient had a fatty replacement of hamstrings with quadriceps still tonics that could promote a biomechanical unbalance and consequently rapid femoro-patellar chondrolysis.

In conclusion, severe and rapid thigh amyotrophy should be considered as a cause a rapid chondrolysis of the patellofemoral joint emphasizing the crucial role of muscular strength in patello-femoral OA development.

Acknowledgment: the authors thank Francis Berenbaum (Saint-Antoine hospital, Paris, France) for his help for the diagnosis and the discussion about this case and Alain Sautet (Saint-Antoine hospital, Paris, France) for the surgical treatment and the discussion.

\section{Conflicts of interest: none}




\section{References}

1. Bennell KL, Wrigley TV, Hunt MA, et al. Update on the role of muscle in the genesis and management of knee osteoarthritis. Rheum Dis Clin North Am 2013; 39:145-76.

2. Toumi H, Best TM, Mazor M, et al.Association between individual quadriceps muscle volume/enthesis and patello femoral joint cartilage morphology. Arthritis Res Ther 2014; 16 :R1

3. Burki V, Patermnotte S, Dougados M, et al. Rapidly destructive tibiofemoral knee osteoarthritis: clinicoradiological presentation and outcome after global medical treatment including nonarthroscopic joint lavage plus corticosteroid injection. A single center retrolective study. Joint Bone Spine 2013;S1297-319X.

4 Batra S, Batra M, McMurtrie A, et al. Rapidly destructive osteoarthritis of the hip joint: a case series. J Orthop Surg Res 2008;3:3

5 Lequesne M, Amouroux J. Rapid destructive coxarthrosis. Presse Med. 1970;78:1435-9.

6. Vanwanseele B, Eckstein F, Knecht H, et al. Longitudinal analysis of cartilage artrophy in the knees of patients with spinal cord injury. Arthritis Rheum 2003;48:3377- 3381.

7. Conroy MB, Kwoh CK, Krishnan E, et al. Muscle strengh, mass, and quality in older men and women with knee osteoarthritis. Arthritis Care Res 2012;64:15-21.

8. Schipplein OD, Andriacchi TP. Interaction between active and passive knee stabilizers during level walking. J Orthop Res 1991;9:113-119.

9. Sharma L, Dunlop DD, Cahue S, et al. Quadriceps strength and osteoarthritis progression in malaligned and lax knees. Ann Int Med 2003;138:613-619. 
10. Sharma L. Examination of exercise effect on knee osteoarthritis outcomes: why should the local mechanical environment be considered? Arthritis Rheum2003;49:255-260. 